\title{
Serapilheira em fragmento florestal de caatinga arbustivo-arbórea fechada
}

\section{Litter in forestry fragment of caatinga in a bush-arboreal closed}

\author{
Daniel Tavares de Farias ${ }^{(D)}$, Francisco Rodolfo da Silva Barreto ${ }^{(D 2}$, Mary Regina de Souza ${ }^{(\mathrm{D})}$, Carlos José \\ da Silva $\mathbb{D}^{4}$ \\ ${ }^{1}$ Graduando em Engenharia Florestal, Universidade Federal Rural do Semi-Árido, Mossoró, Rio Grande do Norte, fone (84) 98173-5851, e-mail: \\ daniel.bky@gmail.com; ${ }^{2}$ Engenheiro Florestal, Natal, Rio Grande do Norte, e-mail: rodolfo_eng.floresta@hotmail.com; ${ }^{3}$ Graduanda em Engenharia Florestal, \\ Universidade Federal Rural do Semi-Árido, Mossoró, Rio Grande do Norte, e-mail: maryrsouz@yahoo.com.br; ${ }^{4}$ Professor Doutor em Ciências Florestais, \\ Universidade Federal Rural do Semi-Árido, Mossoró, Rio Grande do Norte, carlos.silva@ufersa.edu.br.
}

\section{A R T I G O}

Recebido: 11/02/2019

Aprovado: 19/03/2019

\section{Palavras-chave:}

Liteira

Biomassa

Deposição foliar

Sazonalidade

Conservação

\section{Key words:}

Litter

Biomass

Leaf deposition

Seasonality

Conservation

\section{R E S U M O}

O estudo da serapilheira bem como sua produção ao longo da sazonalidade, decomposição e processo da ciclagem de nutrientes podem fornecer informações que contribuem para um melhor entendimento da vegetação e como ocorre a sustentabilidade dos ecossistemas florestais. Diante do exposto objetivou-se avaliar a produção e acúmulo de serapilheira durante o período de 18 meses em um fragmento florestal de caatinga. $\mathrm{O}$ experimento foi conduzido durante o período de 18 meses, de abril de 2016 a setembro de 2017, sob condição de bioma Caatinga. Para isso foram instaladas caixas coletoras a $40 \mathrm{~cm}$ de altura do solo, e tamanho $100 \times 100 \mathrm{~cm}$ para interceptar as seguintes frações: folhas, galhos, estruturas reprodutivas. Para serapilheira acumulada foi utilizando um quadrante de molde vazado de 50 x $50 \mathrm{~cm}$ para retiradas mensais do material disposto sobre o solo. Durante o período de coleta, a produção total de serapilheira foi estimada em $4302,15 \mathrm{~kg} \mathrm{ha}^{-1}$ e a acumulação média de serapilheira sobre o solo na área de estudo foi na ordem de 4603,09 $\mathrm{kg}^{-1} \mathrm{ha}^{-1} \mathrm{ano}^{-1}$. Com as maiores deposições no início do período de estiagem de chuvas. Os resultados apresentados demonstram grande relevância para o desenvolvimento de atividades de manejo ligadas a áreas de caatinga.

A B S T R A C T
The study of plant litter including its production over its seasonality, decomposition and
nutrient cycling process can provide information that contributes to a better understanding
of the vegetation and how the sustainability of forest ecosystems occurs. This study's
purpose was to evaluate the production and accumulation of plant litter during an 18 -month
period in a forest fragment of the Caatinga biome. The experiment was conducted during an
18 -month period, from April 2016 to September 2017 , in the Caatinga biome. For this, 100
$\mathrm{x} 100 \mathrm{~cm}$ collecting boxes were installed at $40 \mathrm{~cm}$ of soil height to intercept leaves,
branches, and reproductive structures. For the accumulated plant litter, a $50 \mathrm{x} 50 \mathrm{~cm}$
bottomless planter box was used for monthly withdrawals of the material laid on the
ground. During the collection period, the total plant litter production was estimated at
$4302.15 \mathrm{~kg}^{-1}$ and the average accumulation of plant litter on the soil in the study area was
approximately $4603.09 \mathrm{~kg}^{-1}$ ha ${ }^{-1}$ year ${ }^{-1}$ with the largest deposits at the beginning of the rainy
season. The results presented in this study demonstrate great relevance for the development
of management activities in the Caatinga biome.

\section{INTRODUÇÃO}

A serapilheira compreende os resíduos orgânicos dispostos sobre o solo, podendo está em vários gradientes de decomposição, sendo formado principalmente, pelo material vegetal, em forma de folhas, galhos, cascas, sementes, frutos e estruturas reprodutivas como flores e inflorescências, e em menor quantidade, os restos e dejetos de animais e artrópodes (CUNHA NETO et al., 2013).

Nos ecossistemas florestais a serapilheira é o principal fator responsável pela manutenção da qualidade física e química

\section{Revista Verde \\ ISSN 1981-8203}

Pombal, Paraíba, Brasil v. 14, n.2, abr.-jun, p.331-337, 2019

doi: 10.18378/rvads.v14i2.6378

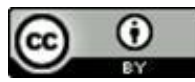


do solo, contribuindo ainda para o desenvolvimento de fungos e bactérias que agem diretamente no processo de decomposição do material, e consequente mineralização dos nutrientes, de forma a fertilizarem o solo, além de servir como banco de sementes, contribuindo para a regeneração da floresta (HENRIQUES et al., 2016; SILVA et al., 2017).

A dinâmica de entrada e saída desse material orgânico no sistema é condicionado por fatores bióticos e abióticos tais como a altitude, latitude, precipitação, temperatura, relevo, estágio sucessional, água e principalmente do tipo de vegetação local (FIGUEREDO FILO et al., 2003).

No Nordeste brasileiro onde cerca de $70 \%$ da região é ocupada por áreas de bioma do tipo caatinga, parte da vegetação exprime características adaptativas do tipo caducifolia, mecanismo fisiológico que permite que as plantas percam total ou parcialmente suas folhas quando se encerra o regime de chuvas (HENRIQUES et al., 2016). De acordo com Moura et al. (2016) é neste período, logo após a quadra chuvosa, que ocorre um maior incremento da biomassa na camada superficial do solo.

Esse bioma caracteriza-se também, pela fragmentação de suas formações florestais, grande biodiversidade florística e arranjos fitossociológicos diversificados, conferindo uma alta complexidade neste tipo de ecorregião (SOUTO, 2006). A caatinga é um dos biomas brasileiros que apresenta altos níveis de degradação, ocasionado principalmente pela intervenção antrópica e uso indiscriminado dos recursos naturais. Neste cenário, a serapilheira que se acumula sobre o solo da floresta, funcionado como controlador térmico e erosivo, dando condições microclimáticas para que plântulas possam emergir, e retardando a degradação do solo pela interceptação da chuva.

A importância de se avaliar a produção e acumulo de serapilheira, está na compreensão do fluxo de entrada e saída desse material no ecossistema, dando subsidio para o entendimento da dinâmica da transferência de nutrientes e o funcionamento da floresta, e para o fornecimento de informações base para projetos de recuperação de áreas degradadas.

Com base no supracitado, recomenda-se o estudo da produção e acumulo de serapilheira, bem como sua decomposição e processo da ciclagem de nutrientes dentro do bioma caatinga por ser um tema de respaldo, podem fornecer informações que contribuem para um melhor entendimento do ecossistema.

Diante do exposto o presente trabalho teve como objetivo avaliar a produção e acúmulo de serapilheira em uma área de reserva legal do bioma Caatinga no município de Mossoró, Rio Grande do Norte.

\section{MATERIAL E MÉTODOS}

O experimento foi conduzido em uma área de reserva legal pertencente a Fazenda Experimental Rafael Fernandes, localizada na comunidade rural Alagoinha (503'37'S; $37^{\circ} 23^{\prime} 50^{\prime}$ " We altitude de $72 \mathrm{~m}$ ), no município de Mossoró-RN. O solo da unidade experimental é classificado como Argissolo Vermelho Distrófico Típico, Latossolo Vermelho Distrófico Argissólico e Plintossolo Argiluvico Eutrófico Típico. (RÊGO et al., 2016). Com base na classificação climática de Köppen, o clima do município de Mossoró é do tipo BSwh', muito quente e com estação chuvosa no verão, temperatura média anual de $27,4^{\circ} \mathrm{C}$ e precipitação pluvial anual muito irregular, com média de $673,9 \mathrm{~mm}$ e umidade relativa do ar de $68,9 \%$ A vegetação pertence ao bioma Caatinga, é classificada como Arbustivoarbórea fechada, de acordo com classificação de Carvalho e Zákia (1994).

Para quantificar a produção mensal de serapilheira total, foi selecionada uma área de um hectare de fragmento florestal de Caatinga, onde foram instaladas dez caixas coletoras a $40 \mathrm{~cm}$ de altura do solo, com tamanho $100 \times 100 \mathrm{~cm}$, feitas de madeira, sendo sua parte inferior revestida de tela de náilon de $2 \mathrm{~mm}$, com o espaçamento entre caixas de $25 \mathrm{~m}$ (Figura 1). O material interceptado pelas caixas coletoras foi recolhido mensalmente durante o período de abril de 2016 a setembro de 2017, o qual após as coletas foi levado ao Laboratório de Conservação Florestal da Universidade Federal Rural do Semi-Árido para separação das frações folhas, galhos, flores e frutos e sementes. Em seguida, o material foi seco em estufa com circulação de ar à temperatura constante de $65{ }^{\circ} \mathrm{C}$ por 72 horas, determinando-se posteriormente seu peso com balança de precisão.

Figura 1. Coletor utilizado para quantificar a serapilheira produzida em fragmento florestal de Caatinga arbustivo-arbórea fechada na área de reserva legal pertencente à Fazenda Experimental Rafael Fernandes no município de Mossoró, Rio Grande do Norte

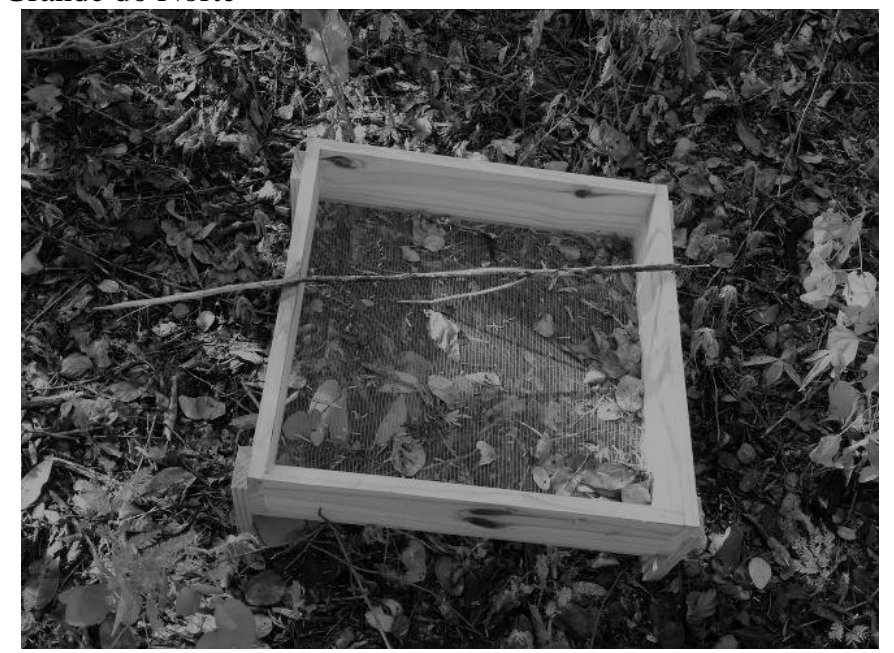

Fonte: Autoria Própria (2017)

Utilizando um quadrante de molde vazado de 50 x $50 \mathrm{~cm}$ foram coletadas as mostras de serapilheira acumulada no solo, sendo cada amostra coletada aleatoriamente nas proximidades das caixas coletoras (Figura 2). Estas seguiram o mesmo procedimento de tratamento da serapilheira produzida para obtenção de suas respectivas massas.

Foi calculada a produção e acumulação mensal das frações (folhas, galhos e sementes) e a serapilheira total. Os valores foram transformados em $\mathrm{kg} \mathrm{ha}^{-1}$ para estimativa mensal e anual da serapilheira produzida e acumulada. Os dados obtidos foram submetidos às análises estatística do coeficiente de Pearson e desvio padrão, para avaliar a dispersão e regularidade dos valores encontrados em função das médias calculadas. 
Figura 2. Quadrante de molde vazado utilizado para coletar a serapilheira acumulada em fragmento florestal de Caatinga arbustivo-arbórea fechada na área de reserva legal pertencente à Fazenda Experimental Rafael Fernandes no município de Mossoró, Rio Grande do Norte

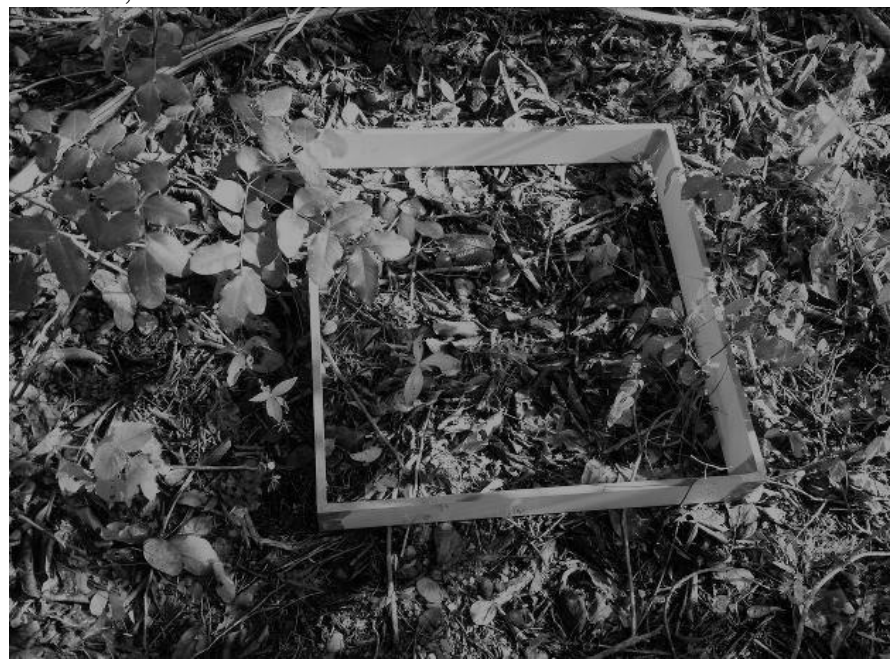

Fonte: Autoria Própria (2017).

\section{RESULTADOS E DISCUSSÃO}

A produção total de serapilheira aportada no fragmento florestal de Caatinga durante os 18 meses foi estimada em $4.302,15 \mathrm{~kg} \mathrm{ha}^{-1}$, e sua deposição mensal e a relação com a precipitação está apresentada na Figura 3.

A produção de serapilheira no primeiro ano de coleta alcançou 1.938,23 kg $\mathrm{ka}^{-1}$ ano $^{-1}$, valor semelhante ao encontrado por Santana e Souto, (2011) quando avaliaram a produção anual de serapilheira em área de Caatinga no mesmo estado. Os valores encontrados também estão em concordância com o estimado pelos autores Costa et al. (2010), quando relatam que em vegetações do tipo Caatinga seja ela arbórea ou arbustiva, tem-se a expectativa de encontrar valores entre 1.500 a $3.500 \mathrm{~kg} \mathrm{ha}^{-1} \mathrm{ano}^{-1}$, o que está sempre correlacionado as adaptações fisiológicas da maioria das espécies e a dinâmica vegetacional da Caatinga (HENRIQUES et al., 2016). Santana (2005) encontrou uma deposição de $2.068,55 \mathrm{~kg} \mathrm{ha}^{-1} \mathrm{ano}^{-1}$ no estado do Rio Grande do Norte, enquanto Souto (2006) encontrou deposições de $1.290,95 \mathrm{~kg} \mathrm{ha}^{-1} \mathrm{ano}^{-1}$ em área de Caatinga no estado da Paraíba. Essa amplitude de valores encontrados para a serapilheira que se deposita sobre o solo ao longo do ano, inclusive no mesmo estado, depende basicamente ecofisiologia local.

Figura 3. Produção mensal de serapilheira na área de reserva legal pertencente à Fazenda Experimental Rafael Fernandes no município de Mossoró, Rio Grande do Norte.

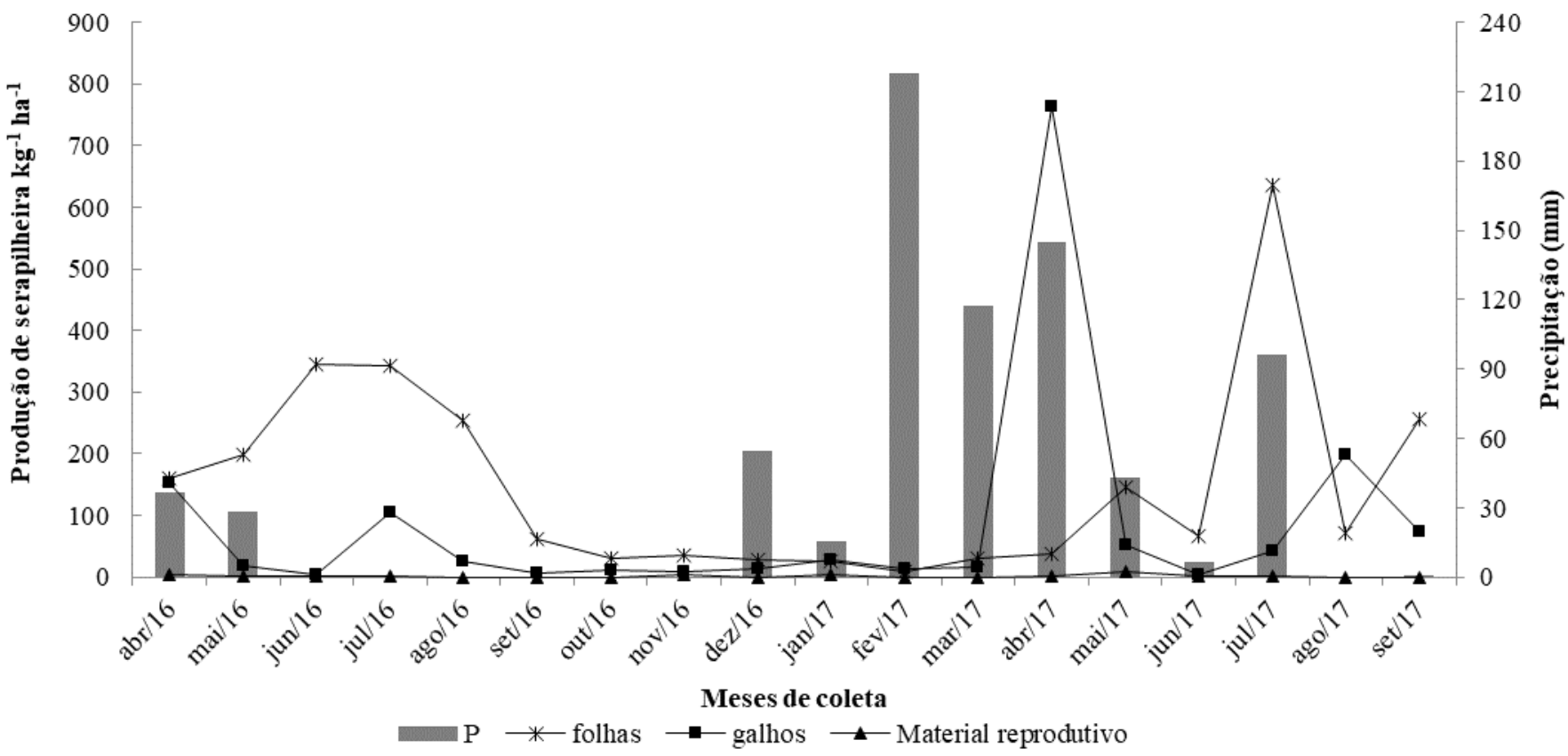

P: Precipitação pluiviométrica

As folhas representam a fração predominante, responsável por $78,71 \%$ do material decíduo (Tabela 1). A maior deciduidade desta fração foi observada nos meses de junho, julho e agosto de 2016 e julho, agosto e setembro de 2017 (Figura 3), indicando caráter sazonal de sua produção e relação direta com a precipitação. Vários pesquisadores como Alves et al. (2006) e Lopes et al. (2009) verificaram comportamento semelhante na produção da fração folhas em diferentes áreas de vegetação natural de bioma Caatinga.

De acordo com a figura 3 os meses de fevereiro a maio de 2017 apresentaram os maiores volumes pluviométricos, neste período observou-se na maioria das espécies florestais o surgimento de novas folhas, e a queda destas logo após a redução dessa disponibilidade hídrica, com maior expressividade da queda de folhas no mês de julho, posterior ao 
mês de menor volume de chuvas. Com base nisso, acredita-se que a produção mensal da fração folha se comporta inversamente proporcional à pluviosidade mensal. E a dinâmica da queda de folhas tem sua variação conforme a transição do período chuvoso ao seco na região Nordeste.

Tabela 1. Produção anual das frações de serapilheira em área de reserva legal pertencente à Fazenda Experimental Rafael Fernandes no município de Mossoró, Rio Grande do Norte

\begin{tabular}{ccc}
\hline Frações da serapilheira & Produção $\left(\mathrm{kg} \mathrm{ha}^{-1}\right)$ & Participação (\%) \\
\hline Folhas & 3895,60 & 56,87 \\
Galhos & 2912,34 & 42,52 \\
Estruturas reprodutivas & 41,66 & 0,61 \\
\hline Total & 6849,63 & 100 \\
\hline
\end{tabular}

$\mathrm{O}$ aporte anual de galhos representou nesta pesquisa a segunda maior $(42,52 \%)$ porção de material que compõem a serapilheira no fragmento de Caatinga estudado (Tabela 1), com pico de produção no mês de abril de 2016 e 2017, no fim da época de chuva e elevação das temperaturas, o que pode ter contribuído para este resultado. Visto que as chuvas de maneira geral são acompanhadas de ventos, o que pode favorecer a produção dessa fração. Além disso, a estação seca, marcada pela intensa restrição hídrica, pode ter promovido o ressecamento de galhos, tornando-os mais susceptíveis a quebra pela ação acentuada dos ventos.

Contudo, a quantidade de galhos que caem das árvores não está somente atrelada a fatores abióticos como também bióticos, assim como a interação de ambos. Neste sentido, compreendese que a acentuada velocidade do vento somada ao déficit hídrico durante o período que antecedeu as análises são de maior relevância para justificar a queda de galhos, e além disso destaca-se a presença de aves em toda área de estudo, e estas podem ter contribuindo com dinâmica do fluxo de entrada de pequenos ramos no sistema serapilheira-solo.

Segundo Oliveira et al. (2012) a velocidade do vento na cidade de Mossoró-RN, chega a valores entre $1,78 \mathrm{~ms}^{-1}$ e 2,88 $\mathrm{ms}^{-1}$ sendo registrado aumento considerável nesta variável climática a medida em que o regime hídrico se intensifica.

Santana e Souto (2011) encontraram uma proporção de biomassa proveniente da fração galhos na ordem de $9,27 \%$, assim como Holanda et al. (2017) que estudando produção de serapilheira em um remanescente de Caatinga, Pombal - PB também encontraram proporção semelhante $(9,31 \%)$, ou seja, valor muito inferior ao $42,52 \%$ encontrado na presente pesquisa, isto pode estar associado a velocidade do vento que na cidade de Mossoró-RN é mais intenso que nas demais áreas estudadas. Porém, estudos realizados no bioma mostra que há oscilações e ausência da padronização na produção de galhos para compor a serapilheira (FERNANDES; SCARAMUZZA, 2007; LOPES et al., 2009). No mês de abril de 2017 foi registrado um valor discrepante na produção de galhos, e isso pode ser resultado da queda de árvores que ocorreu no local de amostragem dias anteriores a coleta referente ao mês de abril de 2017, o que pode ter contribuído para obtenção desse valor discordante dos demais observados mensalmente.

A biomassa de material reprodutivo representou um montante de $41,66 \mathrm{~kg}^{-1}$ ano ${ }^{-1}$, menos de $1 \%$ do volume total da serapilheira produzida anualmente (Tabela 1). E os valores mensais bem diversificados ao longo da amostragem. Segundo Lopes et al. (2009) isso pode ocorrer devido a diversidade florística, fenofases e fitomorfologia do ambiente, responsáveis pelas variações da produção ao longo ano. Esses resultados são muito inferiores aos observados por Costa et al. (2007) e Souto (2006), para estudos realizados nesse mesmo bioma.

Figura 4. Produção mensal do material reprodutivo de serapilheira em área de reserva legal pertencente à Fazenda Experimental Rafael Fernandes no município de Mossoró, Rio Grande do Norte.

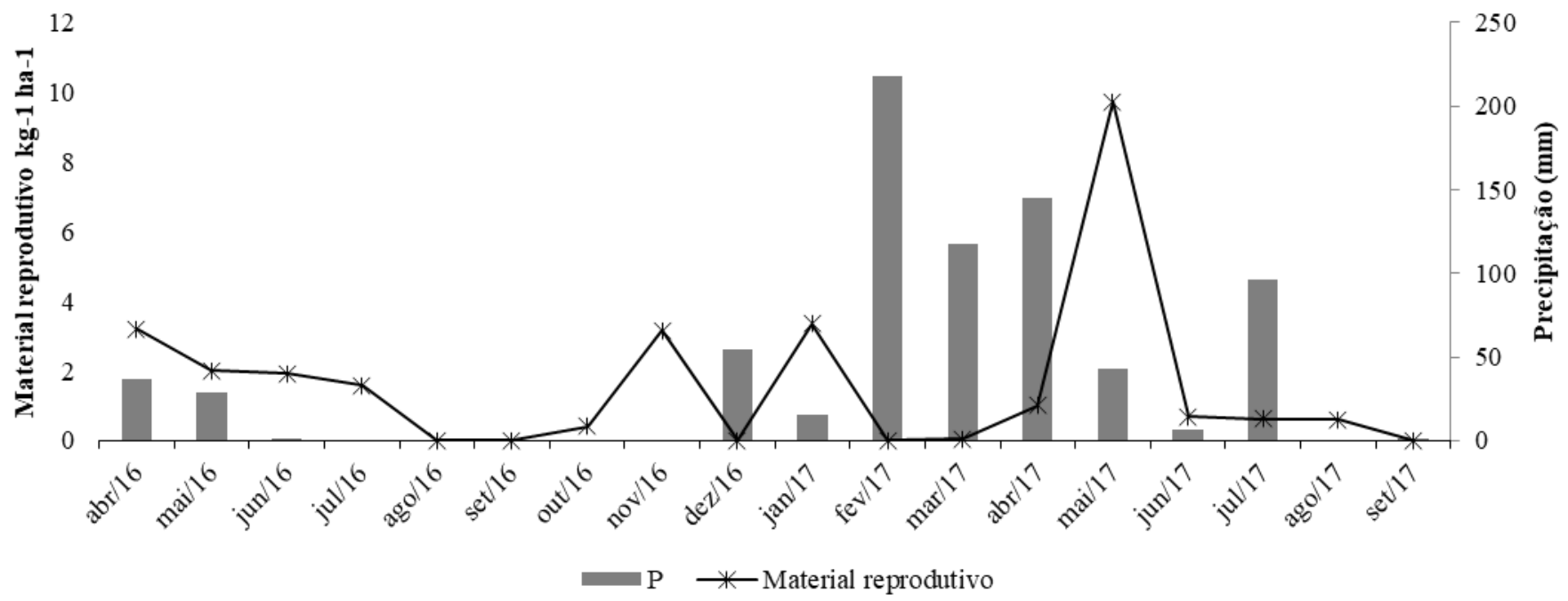

P: Precipitação pluiviométrica

De acordo com Marengo et al. (2016), a baixa produção desse material pode está relacionada com fenômenos naturais que ocorrem na região, como as secas, alteração do regime hidrometeorológico, ou as condições edafoclimáticas. Dessa forma, a ausência de chuvas desde o ano de 2012 e a maior intensificação desse período de estiagem no ano de 2015 , pode 
ter contribuído para a baixa produção de flores, frutos e sementes nos anos subsequentes. A pequena contribuição dessas estruturas na serapilheira pode servir de alerta para que pesquisas relacionadas a regeneração e a emergência de plântulas possam ser realizadas na área, afim de entender o comportamento fenológico das espécies.

A quantidade média do estoque de serapilheira acumulada sobre o solo na reserva legal estudada foi de $4603,09 \mathrm{~kg}^{-1} \mathrm{ha}^{-1}$. $\mathrm{O}$ acúmulo de serapilheira em ecossistemas florestais está sempre associado a uma série de fatores ambientais que atuam de forma conjunta no ambiente, em que sua composição e quantificação variam no tempo e espaço. Esse comportamento de sazonalidade pode ser justificado pela diminuição da disponibilidade de água no solo para as plantas e consequente perda das folhas, proporcionando maiores taxas de deposição de serapilheira (MOURA et al., 2016; SILVA et al., 2017).
A análise paramétrica dos componentes da serapilheira acumulada sobre o solo mostrou que a quantificação da fração folhas pode ser explicada pela precipitação pluvial mensal, uma vez que esta apresentou forte correlação com a precipitação, sendo que a queda das folhas é inversamente proporcional a ocorrência de chuvas (Figura 5).

Os maiores valores de folhas são observados nos meses de julho e agosto do primeiro ano, quando o déficit hídrico se intensifica e as plantas entram em estado de senescência foliar culminando na abscisão das folhas como estratégia adaptativa para evitar a perda de água por transpiração. A sazonalidade desse processo pode ser observada na Figura 5, sendo verificada também em outros trabalhos realizado em áreas análogas (SILVA et al., 2017).

Figura 5. Acumulação mensal de serapilheira na área de reserva legal pertencente à Fazenda Experimental Rafael Fernandes no município de Mossoró, Rio Grande do Norte.

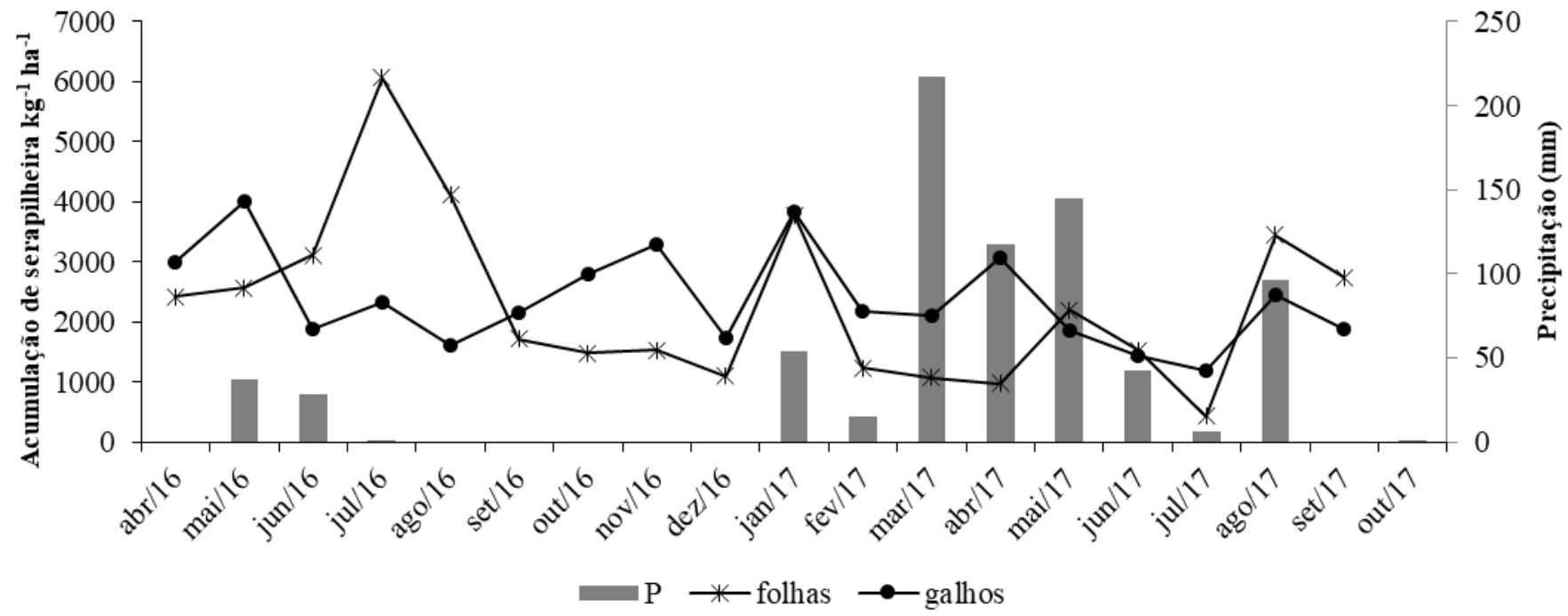

P: Precipitação pluiviométrica

O conteúdo de folhas cumulada sobre o solo, é um dado de grande relevância o entendimento do ecossistema local e tem relação direta com a qualidade química e física do solo, e via de regra sua presença influencia diretamente na qualidade nutricional dos sítios florestais. Uma vez que, esta é a principal via de nutrição dos solos tropicais, e a dinâmica de entrada e mineralização do material vegetal que se acumula no solo variam em função do regime pluviométrico, temperatura e as características morfofisiológicas intrínsecos das plantas do bioma Caatinga (SOUTO, 2006).

Para o componente galho não foi observado significância no coeficiente de correlação (Tabela 2). Contudo, foi o material de maior representatividade, contribuindo com 50,39\% da composição da serapilheira total, tendo ocorrido os picos de acumulação nos meses em que se verificam também as máximas de precipitação (Figura 5), isso porquê as chuvas normalmente são acompanhadas de ventos e seu efeito mecânico é um dos principais fatores que influenciam na deciduidade de ramos de diferentes tamanhos que possivelmente dispusessem da perda de umidade durante o período de déficit hídrico e elevadas temperaturas atmosféricas.

Tabela 2. Coeficientes de Pearson, entre os componentes da serapilheira da reserva legal pertencente à Fazenda Experimental Rafael Fernandes no município de Mossoró, Rio Grande do Norte.

\begin{tabular}{ccccc}
\hline Material & Folhas & Galhos & $\begin{array}{l}\text { Material } \\
\text { reprodutivo }\end{array}$ & Serapilheira \\
\hline R & $-0,5309$ & $-0,0744^{\text {ns }}$ & $-0,1734^{\text {ns }}$ & $-0,4679$
\end{tabular}

Serapilheira (soma das folhas + galhos + Material reprodutivo); ${ }^{\mathrm{ns}}=$ não significativo ao nível de $1 \%$ de probabilidade.

As estruturas reprodutivas representaram apenas $0,7 \%$ da serapilheira acumulada, equivalente a $456,53 \mathrm{~kg} \mathrm{ha}^{-1} \mathrm{com}$ maiores produções nos meses de outubro e novembro de 2016 (Figura 6). Esta fração é composta de flores, frutos e sementes, tornando a serapilheira fonte de propágulos vegetativos que 
contribuem para a regeneração das matas e manutenção da diversidade florística, uma vez que, esta fração é dependente das condições microclimáticas, heterogeneidade temporal e fenológica dos indivíduos vegetais que compõem a paisagem formando sobre o solo um banco de sementes com alta riqueza de espécies, sobretudo nativas (SANTOS et al., 2013; RIBEIRO, 2017).

Figura 6. Acumulação mensal do material reprodutivo de serapilheira em área de reserva legal pertencente à Fazenda Experimental Rafael Fernandes no município de Mossoró, Rio Grande do Norte.

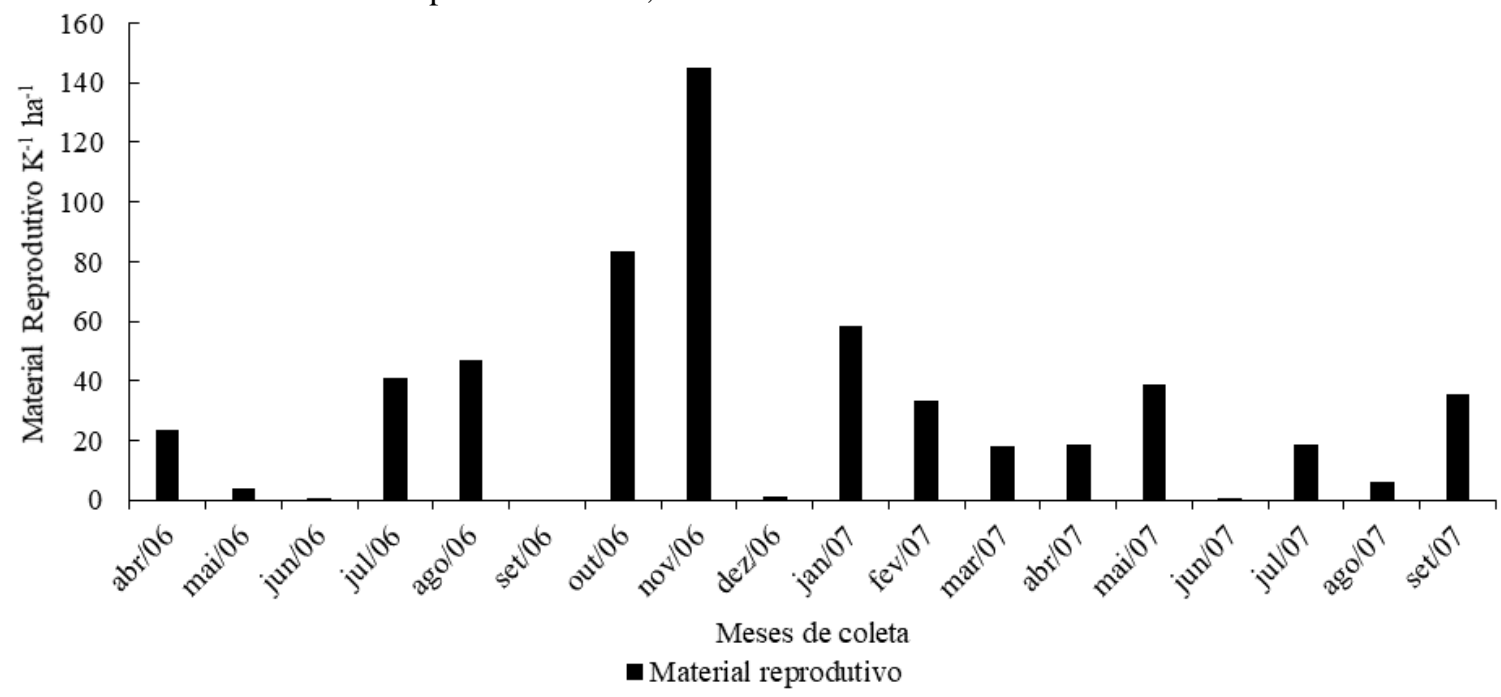

\section{CONCLUSÕES}

A produção de serapilheira primordialmente folhas, apresenta caráter sazonal e uma forte relação com o regime pluviométrico, sendo seu ápice de produção imediatamente após o período chuvoso, em razão da estratégia adaptativa da maioria das espécies que compõem as fitopaisagens em áreas de caatinga.

O estoque de serapilheira acumulada sobre o solo está fortemente condicionado pela distribuição pluviométrica mensal, apresentando caráter sazonal e tendo a fração folhas como material de maior contribuição percentual.

\section{REFERÊNCIAS}

ALVES, A. R.; SOUTO, J. S.; SOUTO, P. C.; HOLANDA, A. C. Aporte e decomposição de serrapilheira em área de caatinga, na Paraíba. Revista de Biologia e Ciências da Terra, v. 6, n. 2, p. 194-203, 2006.

CABIANCHI, G. M. Ciclagem de nutrientes via serapilheira em um fragmento ciliar do rio Urupá, Rondônia. 2010. 101f. Dissertação (Mestrado em Química na Agricultura e Meio Ambiente) Universidade de São Paulo, Piracicaba, 2010.

CARMO FILHO F.; OLIVEIRA, O. F. Mossoró: um município do semi-árido nordestino, caracterização climática e aspecto florístico. Mossoró: ESAM, (Coleção Mossoroense, série B) 62p. 1995.

CARVALHO, A. J. E.; ZÁKIA, M. J. B. Avaliação do estoque madeireiro: etapa final - inventário Florestal do Estado do Rio Grande do Norte. Natal: IBAMA, 1994. 84 p. (Projeto
PNUD/FAO/IBAMA/ GOVERNO DO RIO GRANDE DO NORTE; Documento de Campo, 13).

COSTA, C. C. A.; CAMACHO, R. G. V.; MACEDO, I. D.; SILVA,P. C. M. Análise comparativa da produção de serapilheira em fragmentos arbóreos e arbustivos em área de Caatinga na Flona de Açu, RN. Revista Árvore, v. 34, n. 2, p. 259-265, 2010.

CUNHA NETO, F. V.; LALES, P. S. S.; PEREIRA, M. G.; BELlumath, V. G. H.; ALONSO, J. M. Acúmulo e decomposição da serapilheira em quatro formações florestais. Ciência Florestal, v. 23, n. 3, p. 379-387, 2013. $\underline{10.5902 / 1980509810549 .}$.

FERNANDES, F. C. S.; SCARAMUZZA, W. L. M. P. Produção e decomposição da liteira em fragmento florestal em Campo Verde (MT). Revista de Ciências Agrárias, Belém v. 47, n. 1, p. 173-186, 2007.

FIGUEIREDO FILHO, A.; MORAES, G. F.; SCHAAF, L. B.; FIGUEIREDO, D. J. Avaliação estacional da deposição de serapilheira em uma floresta ombrófila mista localizada no sul do Estado do Paraná. Ciência Florestal, v.13, p.11-18, 2003.

HENRIQUES, Í. G. N.; SOUTO, J. S.; SOUTO, P. C.; SANTOS, W. S.; HENRIQUES, I. G. N.; LIMA, T. S. Acúmulo, deposição e decomposição de serrapilheira sob a dinâmica vegetacional da Caatinga em Unidade de Conservação. Revista Verde de Agroecologia e Desenvolvimento Sustentável, v. 11, n. 1, p. 84-89, 2016. $\underline{10.18378 / \text { rvads.v11i1.4523. }}$. 
HOLANDA, A. C.; FELICIANO, A. L. P.; FREIRE, J. P.; SOUSA, F. Q.; FREIRE, S. R. O.; ALVES, A, R. Aporte de serapilheira e nutrientes em uma área de caatinga. Ciência Florestal, v. 27, n. 2, p. 621-633, 2017.

LOPES, J. F. B; ANDRADE, E. M.; LOBATO, F. A. DE O.; PALÁCIO, H. A. Q.; ARRAES, F. D.-Deposição e decomposição de serapilheira em área da Caatinga. Revista Agro@ mbiente on-line, v. 3, n. 2, p. 72-79, 2010. $\underline{10.18227 / 1982-8470 \text { ragro.v3i2.252. }}$.

MARENGO, J. A.; CUNHA, A. P.; ALVES, L. M. A seca de 2012-15 no semiárido do Nordeste do Brasil no contexto histórico. Climanálise, v. 3, p. 49-54, 2016.

MOURA, M. M. S.; COSTA, G. B. R.; PALÁCIO, H. A. D. Q.; ARAÚJO NETO, J. R. D.; BRASIL, J. B. Produção de serapilheira e suas frações em área da Caatinga no Semiárido Tropical. Revista Brasileira de Gestão Ambiental e Sustentabilidade, Revista Brasileira de Gestão Ambiental e Sustentabilidade, v. 3, n. 5, p. 199-208, 2016.

OLIVEIRA, F. L.; DIAS, V. H. P.; COSTA, E. M. DA., FILGUEIRA, M. A.; SOBRINHO, J. E. Influência das variações climáticas na atividade de vôo das abelhas jandairas Melipona subnitida Ducke (Meliponinae). Revista Ciência Agronômica, v. 43, n. 3, p. 598-603, 2012.

PORTES, M. C. G.; KOEHLER, A.; GALVÃO, F. Variação sazonal da deposição de serapilheira em uma Floresta Ombrófila Densa Altomontana no Morro do Anhangava-PR. Floresta, v. 26, n. 1 p. 3-10, 1996.

RÊGO, L. G. S.; MARTINS, C. M.; SILVA, E. F.; SILVA, J. J.; LIMA, R. N. S. Pedogenesis and soil classification of an experimental farm in Mossoró, state of Rio Grande Do Norte, Brazil. Revista Caatinga, v. 29, n. 4, p. 1036-1042, 2016. 10.1590/1983-21252016v29n430rc.

RIBEIRO, T. O.; BAKKE, I. A.; SOUTO, P. C.; BAKKE, O. A.; LUCENA, D. S. Diversidade do banco de sementes em diferentes áreas de Caatinga manejadas no semiárido da Paraíba, Brasil. Ciência Florestal, Santa Maria, v. 27, n. 1, p. 203-213, 2017.

SANTANA, J. A. S. Estrutura fitossociológica, produção de serapilheira e ciclagem de nutrientes em uma área de Caatinga no Seridó do Rio Grande do Norte. 2005. 184 f. Tese (Doutorado em Agronomia) Universidade Federal da Paraíba, Areia, 2005.

SANTANA, J. A. S.; SOUTO, J. S. Produção de serapilheira na Caatinga da região semi-árida do Rio Grande do Norte, Brasil. Idesia,v. 29, n. 2, p. 87-94, 2011.

SANTOS, D. M.; SILVA, K. A.; ALBUQUERQUE, U. P.; Santos, J. M. F. F.; Lopes, C. G. R.; Araújo, E. L. Can spatial variation and inter-annual variation in precipitation explain the seed density and species richness of the germinable soil seed bank in a tropical dry forest in north-eastern Brazil? Flora, v. 208, n. 7, p. 445-452, 2013.

SILVA, W. T. M.; LEONARDO, F. A. P.; SOUTO, S. J.; SOUTO, LUCENA, J. D. S.; MEDEIROS NETO, P. H. Deposição de serapilheira em áreas de Caatinga no Núcleo de Desertificação do Seridó. Agropecuária Científica do Semiárido, v. 12, n. 4, p. 383-390, 2017. $\underline{10.30969 / a c s a . v 12 i 4.861 .}$

SOUTO, P. C. Acumulação e decomposição da serapilheira e distribuição de organismos edáficos em área de Caatinga na Paraíba, Brasil. 2006. 146 f. Tese (Doutorado em Agronomia) Universidade Federal da Paraíba, Areia, 2006. 